\title{
ASSESSMENT OF HEALTH AND SAFETY SOLUTIONS AT A CONSTRUCTION SITE
}

\author{
Titas DĖJUS, Jurgita ANTUCHEVIČIENE் \\ Department of Construction Technology and Management, Vilnius Gediminas Technical University, \\ Sauletekio al. 11, LT-10223 Vilnius, Lithuania
}

Received 3 Jan. 2013; accepted 22 May 2013

\begin{abstract}
To design solutions for occupational safety at a construction site for the construction technology project, an occupational hazard was assessed. Possible solutions for occupational safety depend on the number of criteria such as hazardous factors from which workers must be protected; the number of danger zones; architectural-design and structural solutions of a building; types of technical protection measures, etc. A large set of solutions for occupational safety predetermines the number of respective typical (or repeated) solutions, which are based on specific technical safety measures and are applicable depending on a hazardous factor; besides, it determines systematisation of the solutions on these grounds. It is suggested to use the Multiple Criteria Decision Making (MCDM) technique for assessment and selection of appropriate solutions for occupational safety. The authors propose formulating assessed alternatives from the typical solutions to ensure their quality and then apply the entropy method for determining relative significances of evaluation criteria and, finally, use Weighted Aggregated Sum Product Assessment (WASPAS) method for ranking of alternatives.
\end{abstract}

Keywords: construction site; occupational hazard; occupational safety; risk; health and safety solutions; MCDM; entropy; WASPAS.

Reference to this paper should be made as follows: Dejjus, T.; Antuchevičienè, J. 2013. Assessment of health and safety solutions at a construction site, Journal of Civil Engineering and Management 19(5): 728-737.

http://dx.doi.org/10.3846/13923730.2013.812578

\section{Introduction}

Assessment of occupational hazards as well as assurance of occupational safety at a construction site is an extremely important question to be analysed. It has been estimated that every third occupational fatality or injury occurs at a construction site. Also, in comparison to other areas of economic activities, many more violations of regulatory enactments on health and safety are registered in the construction sector (Naujalis 2009; Mitropoulos, Memarian 2012).

Scientific and legal literature largely focuses on solutions to different issues pertaining to health and safety at work. Mitropoulos and Memarian (2012) emphasise teamwork as the key strategy for accident prevention in construction crews. Inyang et al. (2012) analyse ergonomic aspects of workers executing daily construction tasks. Silva and Jacinto (2012) analyse the occupational accident patterns and propose the strategies for improving safety. It is emphasised that more investigations should be undertaken to reveal options for improving education and training effectiveness of construction workers in the area of health and safety (Houtman, Bakker 1991; Tartilas 2008; Choudhry 2012).

In general, accidents at construction sites could be qualified as defects of the health and safety management system, which occur due to a number of aspects, including technical, technological, organisational and other types of factors (Dejus 2007, 2011). Such multiple criteria aspects of risk and safety in construction or reconstruction works have been analysed by Bitarafan et al. (2012) and Fouladgar et al. (2012). Besides, any unwanted construction event is usually related to health and safety solutions established in technological work cards of the construction technology project.

This article addresses the reasons of accidents at construction sites and possible preventive measures. First, discussion on health and safety training (learning) for construction workers is presented. Next, a number of real construction accidents as well as their reasons are investigated. Strengths and weaknesses of a number of typical (or repeated) occupational safety solutions are discussed. It is suggested to select the

Corresponding author: Jurgita Antuchevičienė

E-mail: jurgita.antucheviciene@vgtu.lt 
optimal solution for every particular case, assessing several possible typical solutions considering a number of criteria and applying the entropy method for determining relative significances of these criteria as well as Weighted Aggregated Sum Product Assessment (WASPAS) method for multiple criteria ranking of alternatives.

\section{Survey on the health and safety training (learning) for construction workers}

Usually, there are two main reasons behind unsafe behaviour at work: (1) insufficient information regarding safety ('I don't know') and (2) careless attitude towards safety ('I don't care'). Consequently, the number of accidents at work may be reduced with increased health and safety awareness of employees, i.e. with the help of training (Teo et al. 2005; Yang, Ju 2012).

Fundamental reasons that diminish occupational safety in the construction sector are first and foremost related to attitude of workers and inappropriate behaviour, followed by relative or supposed lack of funds, inappropriate equipment that fails to correspond to health and safety requirements, unfit construction management model and choice of inadequate subcontractors (Liaudanskiene et al. 2010).

Health and safety should be monitored in a much stricter manner; all construction workers should be instructed on workplace related occupational hazards and outcomes at all times. Even before construction works start, workers should be instructed on the current situation and possible hazards (Stankiuviene et al. 2008).

Following the applicable regulatory enactments on occupational health and safety, formal training is organised for construction workers in Lithuania (Law on Safety and Health at Work of the Republic of Lithuania 2003). The course involves training and certification on occupational health and safety, namely, students of higher and advanced vocational education and training schools are trained on occupational health and safety requirements in accordance to their speciality and occupation. Considering the attention given by the government on occupational safety, construction workers should be well trained on occupational safety issues. Consequently, the growing number of accidents at work suggests the inefficiency of training rather than its insufficiency (Dejus 2007).

Some countries encourage workers to participate in a variety of training programmes. Numerous methods exist for occupational safety training/learning (Xie et al. 2012): reading (text, diagrams and figures); listening to live lectures on occupational safety; watching video recordings concerned with assurance of industrial safety; and participating in distance learning classes (which are becoming especially effective nowadays).

A survey undertaken in Kentucky (USA) demonstrated the relevance of simulation exercises in small construction companies with less than 10 workers, imitating traumas that can occur at a construction site (Wojcik 2003). Narrative simulations are reality-based exercises that allow experiencing a certain situation. Participants have to respond to questions about the course of events or probable causes and effects. This method is more effective than didactic teaching as it requires fast response and an appropriate solution. Simulations are capable of changing human behaviour much more effectively than the didactic teaching of the same material.

A group of researchers from Taiwan (Jan et al. 2008) presented a study on a novel system called Construction Safety-based E-learning Management (Con-SEM). The system was used for construction processes accelerating information sharing regarding construction safety learning as well as responding to project-related safety information through the Internet. Essentially, the study aimed to develop safe construction environment based on the e-learning system Con-SEM.

Hung et al. (2013) explored training needs through interviews among subcontractors and suggested the need for informal jobsite safety training to complement what had been covered during the formalised safety training.

In summary, the aforementioned experience suggests the need to increase the efficiency of training. Improvements to health and safety training of construction specialists should consider the content of specific training programmes, which should be focused on solutions for completely realistic and exceptionally practical tasks. Training should be built on methodologies with interactive teaching methods, modelling of situations, visualisation techniques, including databases and catalogues of repeatedly used solutions for occupational safety.

\section{Occupational safety solutions for road construction cases}

Occupational safety solutions for road construction cases are discussed as a possible example of repeatedly used solutions. Usually, work zones have to be established and set up for maintenance projects in order to avoid traffic interruptions in situations with some lanes closed and others still in operation (Huang, Shi 2008). In a two-lane two-way segment, one lane gets closed at a time while another continues to be used for traffic, alternating directions through the work zone and ensuring continuous traffic. First, vehicles from one side of the road get to pass through the work zone for a certain period of time and are then blocked while vehicles from the other direction are 
allowed to pass through the work zone for some period of time and the process gets repeated again. This allows vehicles from both sides alternately to pass through the work zone. This situation is similar to the cycles at signalised intersections.

Inevitably, this process results in queuing delays in both directions; however, such work zone properties are particular in road segments of the kind.

A diagram for works undertaken in the centre of a road (with the need to ensure a two-way traffic with $35 \mathrm{mph}$ or less) is provided in Figure 1 (Transportation Information Center 2013). Similar diagrams are offered by Gannapathy et al. (2009) also in Instructions on Fencing of Road Worksites and Traffic Control T DVAER 12 (2012).

In principle, the purpose of the aforementioned diagrams is to organise traffic during road works rather than protect workers from possible hazards. It should be noted that traffic control based on typical diagrams impacts on traffic safety; however, they mostly focus on safety of third parties - drivers and passengers - rather than road maintenance workers.

Furthermore, it should be underlined that the diagrams do not indicate or discuss the priority or order of their implementation; thus, a possibility exists for workers to suffer from accidents during the

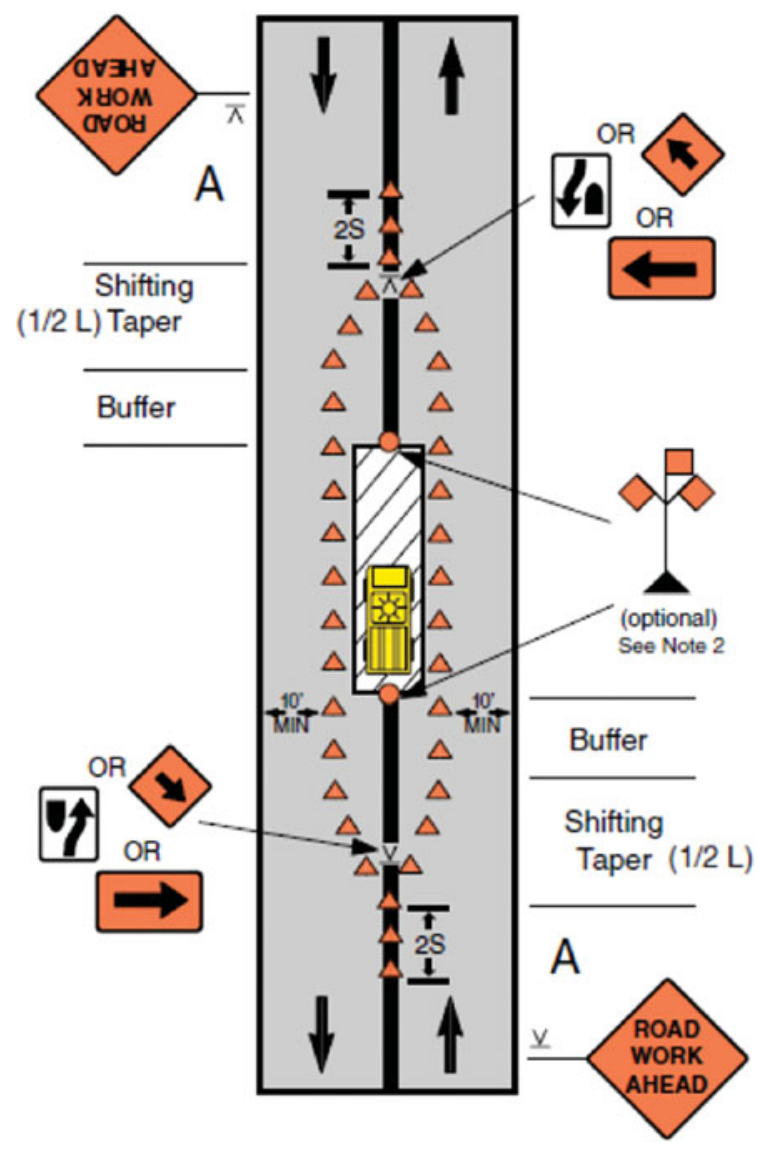

Fig. 1. Typical diagram of a work zone located at the centre of a road (Transportation Information Center 2013) preparatory stage, namely, while mounting road signs or other technical devices.

The aforementioned diagrams help protecting road workers from passing vehicles; although, technical devices indicated on diagrams do not guarantee complete restriction of vehicles from accessing the work zone with workers but rather diminish the possible risk.

It should also be noted that the aforementioned diagrams do not provide information on technical measures that should protect road workers from hazards existing on the site, such as road construction mechanisms or vehicles carrying construction materials as a significant share of accidents at road construction sites occur due to workers coming into contact with machinery.

\section{Occupational safety solutions for general construction works}

Usually, several technological processes may take place at a construction site at the same time, which results in overlapping hazard zones where accidents may occur due to a number of operating machines (Dejjus 2009).

Technological work cards are designed for delivery of separate works as construction processes differ in terms of technology, complexity of health and safety solutions, and most importantly - hazard that impacts on workers at a site as well as specifics related to set-up of workplaces. Thus, solutions for occupational safety are prepared separately for each specific workplace or field of work; while for another field of work, the designed solutions could be adjusted considering specific differences of a workplace (Dejjus 2011). Implementation of specific solutions at a real construction site may depend on the way they are presented. It is best to follow the $3 \mathrm{~S}$ principle (Dejus 2009), which suggests depicting solutions for occupational safety on the construction site plan, in the section of a particular workplace as well as on the third drawing, which provides an element or component of a technical protection measure to be mounted or used or the view from the opposite side. In terms of technological work cards, comprehensibility might be regarded as one of quality assessment criteria.

As an example, data on occupational accidents at construction sites of Lithuania due to trench cave-in are provided. Construction accidents that occurred during the period 2002-2012 were randomly selected. The investigation focused on the total of 22 occupational accidents related to excavation of soil. However, two accidents were rejected from farther analysis as they occurred due to inappropriate trench shoring, while in the remaining cases no such systems were used. In the latter cases, stability of trenches was secured by required sloping. In each specific case, the required sloping angle may be described by the ratio 
of the actual width of a trench at the top and the projected width.

Data provided in Figure 2 show that in all 20 cases that were investigated, the actual widths at the top were less than the projected/standard value, while their actual values ranged from 84 to $17 \%$ of the projected trench width. It should be underlined that only $20 \%$ of investigated cases had the trench width at the top, which was more than half of the projected width; this being too narrow and causing injuries and frequent fatalities of workers.

Investigations of accidents revealed that in all cases, appropriate solutions for occupational safety were not prepared in construction technology projects (or the projects were not designed at all), although use of such solutions during management and delivery of trench excavation works would have created organisational preconditions that would have allowed avoiding accidents and significantly reducing the hazard levels. In such cases, stability of trench slopes is ensured without additional boxing or shoring equipment as slopes are sufficiently shallow and the cave-in hazard is eliminated by removing the soil for safe keeping next to the trench at the initial stage of excavation. Consequently, the design and use of such relatively simple solution (which could be easily and comprehensively depicted) can fully guarantee safe trench operation and avoid situations when a trench caves-in or workers get trapped under soil.

\section{Repeatedly used solutions for occupational safety and principles for systemising/cataloguing}

As it was stated in previous sections of the paper, application of systemised repeated solutions could be helpful when increasing occupational safety at a construction site. Accordingly, principles for systemising potential solutions and selecting the optimal one are proposed and described next.

Annex 1 of the Technical Construction Regulation STR 1.08.02:2002 'Construction works' of the Republic of Lithuania (2002) establishes that construction works are grouped into general and specia-

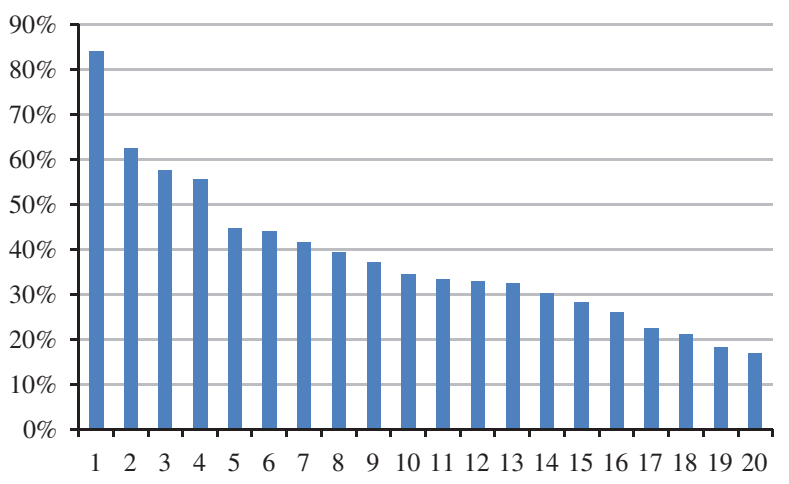

Fig. 2. Ratio between the actual and projected (safe) width of the trench at the top, in percentage lised. In Zavadskas et al. (2006), technological construction processes are grouped into more detailed categories. Therefore, should solutions for occupational safety be prepared for each and every technological process and all construction-site related hazards, the number of typical solutions might amount to a relatively large set.

Such set of solutions for occupational safety seems very similar to a usual set of project solutions, which serves as the point of departure for comparison and assessment of all project alternatives. Thus, Multiple Criteria Decision Making (MCDM) methods could also be successfully used when planning solutions for occupational safety.

In real cases, the aforementioned set of solutions may be limited through reduction of the number of technological processes (as not all construction sites involve the entire set of technological processes), this way limiting the number of related hazards as suggested in Annex 5 of the Instructions on Health and Safety at Construction Sites (2000), i.e. focusing all preventive measures on five hazards - falls, struck by constructions or products, caught in or between mechanisms, cave-in and electrocution - which corresponds to conclusions (Dejus 2009) on identification of possible exposure to risk.

Although even with aforementioned limitations, the number of solutions remains considerably large as each construction site as well as each workplace involves different construction processes and factors as well as diverse technologies required to perform the same tasks, for example, workplaces can be located at different heights and depths; scope of work may vary; hydrogeological and meteorological work conditions may be dissimilar; different constriction materials and building or structural solutions can be used; as well as opportunities of contractors to use as wide and varied arsenal of technical safety measures.

Figure 3 illustrates an example of a possible typical occupational safety solution that is suggested for fall-off and elevator shaft fall hazards.

If workers can access a dangerous zone in front of the elevator shaft (Fig. 3) while mounting the protective fencing, which should be started from the top element, workers must appropriately use P-30 harness and fall prevention device ROLEX.

In relation to Figure 3, it should be underlined that the same workplace may have a number of solutions for occupational safety planned to protect workers from the same most dangerous factor yet using different technical protection measures.

The system of aforementioned solutions comprises the database, which is continuously populated and serves as a basis for the system of typical/repeated solutions, which might also be referred to as a catalogue. 

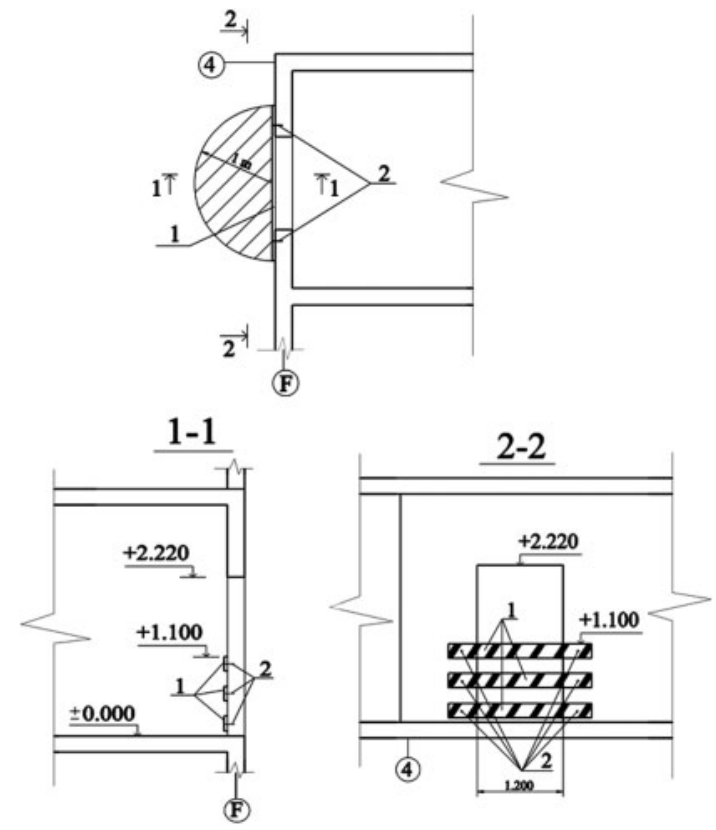

Fig. 3. Occupational safety solution (a workplace diagram and sections): 1 - plank, shaved and painted, length $-1.6 \mathrm{~m}$, width $-0.20 \mathrm{~m}$, thickness $-0.04 \mathrm{~m} ; 2$ - anchor screw in concrete with insert, length $-100 \mathrm{~mm}$, diameter $-8 \mathrm{~mm}$

The suggested catalogue of typical/repeated solutions may be used in a specific construction company. The system of typical solutions could help designing technological work cards or training future construction specialists in design of construction technology projects.

The fundamental advantages of the designed system are as follows: only tested safety solutions are used, and they can be further improved with each next project, considering relevant specific technical measures; construction companies may exchange catalogued information and this way reduce the time required to design solutions for occupational safety; typical solutions for occupational safety can be made available in digital format, thus easily changed and adjusted for each particular building, considering the architectural-design solution and possibilities of a contractor to procure and use certain technical protection measures; in terms of workers, effectiveness of solutions for occupational safety depends on the level of detail and clarity of information, meanwhile the catalogue of typical solutions for occupational safety provides exceptional opportunities to improve each following alternative in terms of specificity and comprehensiveness; the catalogue may be used for health and safety training of specialists as well as workers.

The most rational alternative for a particular case can be selected from the catalogue using MCDM techniques.

\section{Entropy and WASPAS for multiple criteria assessment of solutions for occupational safety}

The main idea of the suggested methodology for assessment and selection of solutions for occupational safety is that alternative solutions should be evaluated in terms of multiple criteria.

The existing situation corresponds to the minimalistic conception of assessment with the rational solution identified on the basis of one criterion, namely, the price for use/realisation/implementation of the solution. Basically, this corresponds to the provision established in the Law on Public Procurement of the Republic of Lithuania (2005) regarding the priority given to the alternative with the least price.

The proposed innovative approach involves mathematical methods; this way allowing the assessment of solutions on the basis of any criteria, any number of criteria and using objective assessment.

It should also be considered that the set of solutions for occupational safety, from which a rational solution is selected, is basically comprised of typical solutions. Consequently, real preconditions are created to not only assess rational solutions but also ensure the quality of the selected alternative.

As a number of criteria are involved, it is proposed to apply the entropy method for determining relative significances of criteria. Next, it is proposed to apply the newly developed precise Weighted Aggregated Sum Product Assessment (WASPAS) method for ranking of alternatives.

The summarised graphic representation of the suggested model for assessment of solutions for occupational safety is provided in Figure 4.

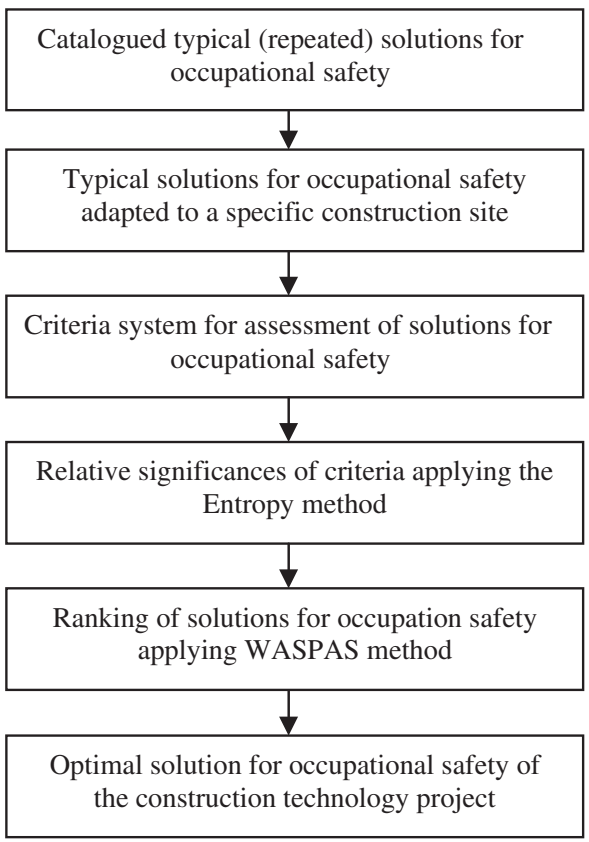

Fig. 4. Summarised model for assessment of solutions for occupational safety at a construction site 


\subsection{Methodology for determining weights of criteria by means of Entropy}

Shannon (1948) initiated the use of entropy in theory of information. Later, entropy was introduced in determination of criteria weights for multiple criteria problems (Ye 2010; Kildiene et al. 2011; Liu, Zhang 2011; Shemshadi et al. 2011; Susinskas et al. 2011; Chen et al. 2012).

Let us suppose that a problem is defined on $m$ alternatives and $n$ decision criteria. The variable $x_{i j}$ stands for the performance value of alternative $i$ when it is evaluated in terms of criterion $j$.

Linear normalisation of initial criteria values $x_{i j}$ is applied and dimensionless values $\bar{x}_{i j}$ are obtained:

$$
\bar{x}_{i j}=\frac{x_{i j}}{\max _{i} x_{i j}},
$$

if $\max _{i} x_{i j}$ value is preferable or

$$
\bar{x}_{i j}=\frac{\min _{i} x_{i j}}{x_{i j}},
$$

if $\min _{i} x_{i j}$ value is preferable.

The level of entropy $E_{j}$ of each criterion is determined as follows:

$$
E_{j}=-\frac{1}{\ln m} \sum_{i=1}^{m} \bar{x}_{i j} \ln \left(\bar{x}_{i j}\right) .
$$

The variability level of $x_{j}$ criterion is determined by:

$$
d_{j}=1-E_{j} .
$$

The relative importance of criteria or weights $w_{j}$ is determined as follows:

$$
w_{j}=\frac{d_{j}}{\sum_{j=1}^{n} d_{j}} .
$$

\subsection{WASPAS}

The joint criterion of optimality called WASPAS is based on two well-known criteria of optimality.

The first criterion of optimality, i.e. criterion of a mean-weighted success is similar to the well-known Weighted Sum Model (WSM). The relative importance of alternative $i$, denoted as $Q_{i}^{(1)}$, is defined as follows (MacCrimon 1968; Triantaphyllou, Mann 1989):

$$
Q_{i}^{(1)}=\sum_{j=1}^{n} \bar{x}_{i j} w_{j}
$$

where linear normalisation of initial criteria values is applied according to Eqns (1) and (2).

The second criterion of optimality, namely, multiplicative exponential generalised criterion, in general coincides with Weighted Product Model
(WPM). The relative importance of alternative $i$, denoted as $Q_{i}^{(2)}$, is defined as follows (Miller, Starr 1969; Triantaphyllou, Mann 1989):

$$
Q_{i}^{(2)}=\prod_{j=1}^{n}\left(\bar{x}_{i j}\right)^{w_{j}} .
$$

The third joint generalised criterion of weighted aggregation of additive and multiplicative methods was proposed by Saparauskas et al. $(2010,2011)$ :

$$
Q_{i}=0.5 Q_{i}^{(1)}+0.5 Q_{i}^{(2)}=0.5 \sum_{j=1}^{n} \bar{x}_{i j} w_{j}+0.5 \prod_{j=1}^{n}\left(\bar{x}_{i j}\right)^{w_{j}} .
$$

As particular methods can produce different ranking results (Antucheviciene et al. 2011, 2012), increasing the ranking accuracy and the effectiveness of decisions is important. Accordingly, methodology for optimisation of weighted aggregated function was proposed and the WASPAS method for ranking of alternatives was presented (Zavadskas et al. 2012):

$$
\begin{aligned}
& Q_{i}^{*}=\lambda_{i} \sum_{j=1}^{n} \bar{x}_{i j} w_{j}+\left(1-\lambda_{i}\right) \prod_{j=1}^{n}\left(\bar{x}_{i j}\right)^{w_{j}}, \\
& \lambda_{i}=0, \ldots, 1, i=1, \ldots, m .
\end{aligned}
$$

Optimal values of $\lambda_{i}$ can be found when searching the extreme of the function:

$$
\lambda_{i}=\frac{\sigma^{2}\left(Q_{i}^{(2)}\right)}{\sigma^{2}\left(Q_{i}^{(1)}\right)+\sigma^{2}\left(Q_{i}^{(2)}\right)} .
$$

The variances $\sigma^{2}\left(Q_{i}^{(1)}\right)$ and $\sigma^{2}\left(Q_{i}^{(2)}\right)$ should be calculated as follows:

$$
\begin{gathered}
\sigma^{2}\left(Q_{i}^{(1)}\right)=\sum_{j=1}^{n} w_{j}^{2} \sigma^{2}\left(\bar{x}_{i j}\right) ; \\
\sigma^{2}\left(Q_{i}^{(2)}\right)=\sum_{j=1}^{n}\left(\frac{\prod_{j=1}^{n}\left(\bar{x}_{i j}\right)^{w_{j}} w_{j}}{\left(\bar{x}_{i j}\right)^{w_{j}}\left(\bar{x}_{i j}\right)^{\left(1-w_{j}\right)}}\right)^{2} \sigma^{2}\left(\bar{x}_{i j}\right) .
\end{gathered}
$$

In the case of normal distribution of initial data with the credibility $q=0.05$, estimates of variances of normalised criteria values are calculated as follows:

$$
\sigma^{2}\left(\bar{x}_{i j}\right)=\left(0.05 \bar{x}_{i j}\right)^{2} .
$$

See Zavadskas et al. (2012) for detailed explanation of Eqns (10)-(13). The simplified application of WASPAS for building modernisation problem can be found in Staniunas et al. (2013). 
Table 1. Initial decision-making matrix

\begin{tabular}{|c|c|c|c|c|c|c|}
\hline Criteria & & $x_{1}$ & $x_{2}$ & $x_{3}$ & $x_{4}$ & $x_{5}$ \\
\hline Optimum & & $\min$ & $\min$ & $\max$ & $\min$ & $\min$ \\
\hline \multirow[t]{6}{*}{ Alternatives $a_{i}$} & $a_{1}$ & 0.51 & 3.21 & 12 & 0.96 & 9 \\
\hline & $a_{2}$ & 0.24 & 4.57 & 4 & 1.92 & 5 \\
\hline & $a_{3}$ & 0.49 & 16.51 & 2 & 3.52 & 7 \\
\hline & $a_{4}$ & 0.12 & 0.74 & 60 & 3.00 & 3 \\
\hline & $a_{5}$ & 3.76 & 52.27 & 3 & 13.02 & 22 \\
\hline & $a_{6}$ & 0.06 & 4.44 & 2 & 0.42 & 9 \\
\hline
\end{tabular}

Table 2. Normalised decision-making matrix

\begin{tabular}{lcccccc}
\hline Criteria & & $x_{1}$ & $x_{2}$ & $x_{3}$ & $x_{4}$ & $x_{5}$ \\
\hline Alternatives $a_{i}$ & $a_{1}$ & 0.12 & 0.23 & 0.20 & 0.44 & 0.33 \\
& $a_{2}$ & 0.25 & 0.16 & 0.07 & 0.22 & 0.12 \\
& $a_{3}$ & 0.12 & 0.04 & 0.03 & 0.14 & 0.03 \\
& $a_{4}$ & 0.50 & 1.00 & 0.05 & 0.00 \\
& $a_{5}$ & 0.02 & 0.01 & 0.03 & 0.14 \\
& $a_{6}$ & 1.00 & 0.17 & & 0.00 \\
\hline
\end{tabular}

Table 3. Determining of weights by means of entropy

\begin{tabular}{lccccc}
\hline Criteria & $x_{1}$ & $x_{2}$ & $x_{3}$ & $x_{4}$ & $x_{5}$ \\
\hline Level of entropy $E_{j}$ & 0.71 & 0.63 & 0.49 & 0.74 & 0.93 \\
Variability level $d_{j}$ & 0.29 & 0.37 & 0.51 & 0.26 & 0.07 \\
Criteria weights $w_{j}$ & 0.20 & 0.25 & 0.34 & 0.17 & 0.04 \\
\hline
\end{tabular}

\subsection{Case study}

An example of the use of the suggested model is provided below. Six typical solutions for occupational safety - all of which correspond to occupational safety requirements established in regulatory enactments are analysed that could be used to protect workers from falls into an elevator shaft during installation works (alternatives $a_{i}, i=1, \ldots 6$ ). In the investigated case, safety was ensured with the help of protective fencing. One of solution alternatives $\left(a_{1}\right)$ is depicted in Figure 3. The other five alternatives have slightly different technological and economic characteristics (Table 1).

Table 4. Searching the extreme of the function

\begin{tabular}{llllr}
\hline $\begin{array}{l}\text { Variances and } \\
\text { optimal values }\end{array}$ & & $\sigma^{2}\left(Q_{i}^{(1)}\right)$ & $\sigma^{2}\left(Q_{i}^{(2)}\right)$ & $\lambda_{i}$ \\
\hline Alternatives $a_{i}$ & $a_{1}$ & $3.57 \mathrm{E}-05$ & $2.95 \mathrm{E}-05$ & 0.45 \\
& $a_{2}$ & $1.66 \mathrm{E}-05$ & $1.31 \mathrm{E}-05$ & 0.44 \\
& $a_{3}$ & $4.01 \mathrm{E}-06$ & $2.57 \mathrm{E}-06$ & 0.39 \\
& $a_{4}$ & $4.74 \mathrm{E}-04$ & $2.40 \mathrm{E}-04$ & 0.34 \\
& $a_{5}$ & $9.51 \mathrm{E}-07$ & $4.99 \mathrm{E}-07$ & 0.34 \\
& $a_{6}$ & $1.74 \mathrm{E}-04$ & $2.27 \mathrm{E}-05$ & 0.12 \\
\hline
\end{tabular}

The price for fencing materials of analysed solutions range from LTL 8.88 to 156.80 (EUR $1=$ LTL 3.4528). However, the price is not the single criterion when selecting the best solution. Alternatives are evaluated in terms of five criteria: $x_{1}-$ costs for installation of the protective fencing, in man hours; $x_{2}$ - price for fencing materials for one operational cycle, in LTL; $x_{3}$ - repeated use of the protective fencing, in cycles; $x_{4}-$ area fenced, in $\mathrm{m}^{2}$ and $x_{5}-$ number of protective fencing elements, in units.

The initial decision matrix with data on all six solutions for occupational safety is provided in the Table 1. Normalised decision-making matrix (applying Eqns (1) and (2)) is presented in Table 2.

Table 5. Relative significances and ranking order of alternatives

\begin{tabular}{lccc}
\hline Alternatives & $\begin{array}{c}\text { Optimal } \\
\lambda_{i}\end{array}$ & $\begin{array}{c}\text { Relative } \\
\text { significances }\end{array}$ & $\begin{array}{c}\text { Ranking } \\
\text { order }\end{array}$ \\
\hline$a_{1}$ & 0.45 & 0.23 & 2 \\
$a_{2}$ & 0.44 & 0.16 & 4 \\
$a_{3}$ & 0.39 & 0.07 & 5 \\
$a_{4}$ & 0.34 & 0.67 & 1 \\
$a_{5}$ & 0.34 & 0.03 & 6 \\
$a_{6}$ & 0.12 & 0.22 & 3 \\
\hline
\end{tabular}


Calculation of criteria weights according to Eqns (3)-(5) is provided in Table 3.

Calculation steps when searching the optimal values of $\lambda_{i}$ applying Eqns (10)-(13) are presented in Table 4.

Established relative significances $Q_{i}^{*}$ (Eqn. 9) and ranking order of alternatives are provided in Table 5.

Searching the increase of ranking accuracy and the effectiveness of decisions, six typical solutions for occupational safety during elevator shaft installation works were assessed applying WASPAS. Once the optimal $\lambda_{i}$ values are determined, the availability as well as the application in real life situations of six analysed alternatives should be as follows: $a_{4} \succ a_{1}=a_{6} \succ a_{2} \succ a_{3} \succ a_{5}$.

\section{Conclusions}

When analysing occupational hazards and occupational safety at a construction site, first, health and safety training of construction workers was studied. It was stated that the growing number of accidents at work is caused by the inefficiency of training rather than its insufficiency.

The authors suggest improving health and safety training of all construction workers and suggest using analysis of the catalogue of typical solutions for occupational safety as an effective method.

Selection of a rational typical solution should be ensured. The investigation revealed that typical solutions for occupational safety are used in the field of road construction; however, they are intended to protect third persons from accessing dangerous zones next to a construction site rather than ensure health and safety of workers.

The importance of the appropriate use of safety solutions was demonstrated when analysing occupational accidents related to excavation of soil. The collected data revealed that cave-in cases in neither boxed nor shored trenches usually occurred due to inappropriately excavated trench slopes, which were too upright in comparison to standards, and trench widths, which were about $20-80 \%$ less at the top in comparison to standard/projected ones.

Construction companies are suggested to use catalogues of typical solutions for occupational safety as they have a number of advantages, including only tested safety solutions are used, and they can be further improved with each next project, considering specific technical protection measures used; construction companies may exchange catalogued information and this way reduce the time required to design solutions for occupational safety during preparation or adjustment of the construction technology project.

It is suggested to select the optimal solution for every particular case assessing several possible typical solutions and considering a number of criteria and applying the entropy method for determining relative significances of these criteria as well as WASPAS method for multiple criteria ranking of alternatives.

A case study for selection of the optimal occupational safety solution for fall-off and elevator shaft fall hazards is presented. The best solution from six possible ones is selected considering a number of important criteria.

\section{References}

Antucheviciene, J.; Zakarevicius, A.; Zavadskas, E. K. 2011. Measuring congruence of ranking results applying particular MCDM methods, Informatica 22(3): 319338.

Antucheviciene, J.; Zavadskas, E. K.; Zakarevicius, A. 2012. Ranking redevelopment decisions of derelict buildings and analysis of ranking results, Economic Computation and Economic Cybernetics Studies and Research 46(2): 37-62.

Bitarafan, M.; Hashemkhani Zolfani, S.; Arefi, S. L.; Zavadskas, E. K. 2012. Evaluating the construction methods of cold-formed steel structures in reconstructing the areas damaged in natural crises, using the methods AHP and COPRAS-G, Archives of Civil and Mechanical Engineering 12(3): 360-367. http://dx.doi.org/10.1016/j.acme.2012.06.015

Chen, L.-H.; Hung, C.-C.; Tu, C.-C. 2012. Considering the decision maker's attitudinal character to solve multicriteria decision-making problems in an intuitionistic fuzzy environment, Knowledge-Based Systems 36: 129138. http://dx.doi.org/10.1016/j.knosys.2012.06.012

Choudhry, R. M. 2012. Implementation of BBS and the impact of site-level commitment, Journal of Professional Issues in Engineering Education and Practice 138(4): 296-304. http://dx.doi.org/10.1061/(ASCE)EI.1943-5541.0000111

Dejus, T. 2007. Accidents on construction sites and their reasons, in Proc. of the 9th International Conference on "Modern Building Materials, Structures and Techniques", 16-18 May, 2007, Vilnius, Lithuania, 241-247.

Dejus, T. 2009. Dangerous factors while installing building constructions and means to decrease their undesirable influence, Engineering Structures and Technologies 1(2): 111-121. http://dx.doi.org/10.3846/skt.2009.14

Dejus, T. 2011. Safety of technological projects using multicriteria decision making methods, Journal of Civil Engineering and Management 17(2): 177-183.

Fouladgar, M. M.; Yazdani-Chamzini, A.; Zavadskas, E. K. 2012. Risk evaluation of tunnelling projects, Archives of Civil and Mechanical Engineering 12(1): 1-12. http://dx.doi.org/10.1016/j.acme.2012.03.008

Gannapathy, V. R.; Subramaniam, S. K.; Mohamad Diah, A. B.; Suaidi, M. K.; Hamidon, A. H. 2009. Risk factors in a road construction site, International Journal of Humanities and Social Sciences 4(8): 622625.

Houtman, I. L. D.; Bakker, F. C. 1991. Individual differences in reactivity to and coping with the stress of lecturing, Journal of Psychosomatic Research 35(1): 11-24. http://dx.doi.org/10.1016/0022-3999(91)90003-7 
Huang, Q.; Shi, J. 2008. Optimizing work zones for two-lane urban road maintenance projects, Tsinghua Science and Technology 13(5): 644-650. http://dx.doi.org/10.1016/S1007-0214(08)70103-2

Hung, Y. H.; Winchester, W. W. III; Smith-Jackson, T. L.; Kleiner, B. M.; Babski-Reeves, K. L.; Mills, T. H. III. 2013. Identifying fall-protection training needs for residential roofing subcontractors, Applied Ergonomics 44(3): 372-380.

http://dx.doi.org/10.1016/j.apergo.2012.09.007

Instructions on Fencing of Road Worksites and Traffic Control TDVAER 12. 2012. Lithuanian Road Administration under the Ministry of Transport and Communications (in Lithuanian).

Instructions on Health and Safety at Construction Sites. 2000. Labour Inspectorate of the Republic of Lithuania (in Lithuanian).

Inyang, N.; Al-Hussein, M.; El-Rich, M.; Al-Jibouri, S. 2012. Ergonomic analysis and the need for its integration for planning and assessing construction tasks, Journal of Construction Engineering and Management ASCE 138(12): 1370-1376.

http://dx.doi.org/10.1061/(ASCE)CO.1943-7862.0000556

Jan, S. H.; Ho, P.; Tserng, H. P. 2008. Developing construction safety-based e-learning management system, in Proc. of CIB W99 International Conference Evolution of and Directions in Construction Safety and Health, 9-11 March, 2008, Gainesville, Florida, 311-319.

Kildiene, S.; Kaklauskas, A.; Zavadskas, E. K. 2011. COPRAS based comparative analysis of the European country management capabilities within the construction sector in the time of crisis, Journal of Business Economics and Management 12(2): 417-434. http://dx.doi.org/10.3846/16111699.2011.575190

Law on Public Procurement of Republic of Lithuania. No. X-471 of 22 December 2005.

Law on Safety and Health at Work of Republic of Lithuania. No. IX-1672 of 1 July 2003.

Liaudanskiene, R.; Varnas, N.; Ustinovichius, L. 2010. Modelling the application of workplace safety and health act in Lithuanian construction sector, Technological and Economic Development of Economy 16(2): 233-253.

http://dx.doi.org/10.3846/tede.2010.15

Liu, P.; Zhang, X. 2011. Research on the supplier selection of a supply chain based on entropy weight and improved ELECTRE-III method, International Journal of Production Research 49(3): 637-646. http://dx.doi.org/10.1080/00207540903490171

MacCrimon, K. R. 1968. Decision making among multiple attribute alternatives: a survey and consolidated approach. Rand Memorandum, RM-4823-ARPA.

Miller, D. W.; Starr, M. K. 1969. Executive decisions and operations research. Englewood Cliffs, NJ: PrenticeHall. 446 p.

Mitropoulos, P.; Memarian, B. 2012. Team processes and safety of workers: cognitive, affective, and behavioral processes of construction crews, Journal of Construction Engineering and Management ASCE 138(10): 1181-1191.

http://dx.doi.org/10.1061/(ASCE)CO.1943-7862.0000527
Naujalis, J. 2009. Review of occupational health and safety in 2005-2008. Labour Inspectorate of the Republic of Lithuania (in Lithuanian).

Saparauskas, J.; Zavadskas, E. K.; Turskis, Z. 2010. Evaluation of alternative building designes according to the three criteria of optimality, in Proc. of 10th International Conference "Modern Building Materials, Structures and Techniques”, 19-21 May, 2010, Vilnius, Lithuania, 519-523.

Saparauskas, J.; Zavadskas, E. K.; Turskis, Z. 2011. Selection of facade's alternatives of commercial and public buildings based on multiple criteria, International Journal of Strategic Property Management 15(2): 189-203. http://dx.doi.org/10.3846/1648715X.2011.586532

Shannon, C. E. 1948. A mathematical theory of communication, The Bell System Technical Journal 27: 379-432.

Shemshadi, A.; Shirazi, H.; Toreihi, M.; Terokh, M. J. 2011. A fuzzy VIKOR method for supplier selection based on entropy measure for objective weighting, Expert Systems with Applications 38(10): 12160-12167. http://dx.doi.org/10.1016/j.eswa.2011.03.027

Silva, J. F.; Jacinto, C. 2012. Finding occupational accident patterns in the extractive industry using a systematic data mining approach, Reliability Engineering \& System Safety 108: 108-122. http://dx.doi.org/10.1016/j.ress.2012.07.001

Staniunas, M.; Medineckiene, M.; Zavadskas, E. K.; Kalibatas, D. 2013. To modernize or not: ecologicaleconomical assessment of multi-dwelling houses modernization, Archives of Civil and Mechanical Engineering 13(1): 88-98.

http://dx.doi.org/10.1016/j.acme.2012.11.003

Stankiuviene, A.; Cyras, P.; Vakriniene, S. 2008. Risk identification in technical regulation, in Proc. of 7 th International Conference on "Environmental Engineering”, 22-23 May, 2008, Vilnius, Lithuania, 341349.

STR 1.08.02:2002 Technical Construction Regulation "Construction Works" of Republic of Lithuania. 2002 (in Lithuanian).

Susinskas, S.; Zavadskas, E. K.; Turskis, Z. 2011. Multiple criteria assessment of pile-columns alternatives, Baltic Journal of Road and Bridge Engineering 6(3): 145-152. http://dx.doi.org/10.3846/bjrbe.2011.19

Tartilas, J. 2008. A critical approach to the labour safety legislation, Jurisprudence 8: 13-17.

Teo, E. A. L.; Ling, F. Y. Y.; Ong, D. S. Y. 2005. Fostering safe work behaviour in workers at construction sites, Engineering, Construction and Architectural Management 12(4): 410-422. http://dx.doi.org/10.1108/09699980510608848

Transportation Information Center. 2013. Work zone safety [online]. Guidelines for construction, maintenance, \& utility operations, University of Wisconsin-Madison [cited 2 January 3013]. Available from Internet: http://epdfiles.engr.wisc.edu/pdf_web_files/tic/hand books/WorkZoneSafety.pdf

Triantaphyllou, E.; Mann, S. H. 1989. An examination of the effectiveness of multi-dimensional decision-making methods: a decision-making paradox, Decision Support Systems 5(3): 303-312. http://dx.doi.org/10.1016/0167-9236(89)90037-7 
Wojcik, S. M. 2003. Performance and evaluation of small construction safety training simulations, Occupational Medicine 53(4): 279-286.

http://dx.doi.org/10.1093/occmed/kqg068

Xie, H.; Tudoreanu, M. E.; Shi, W. 2012. Development of a virtual reality safety-training system for construction workers [online], [cited 27 November 2012]. Available from Internet: http://itc.scix.net/data/works/att/ff9b.content.00092.pdf

Yang, G. S.; Ju, J. 2012. The statistical analysis of safe behavior habits' culturing methods on construction workers, Applied Mechanics and Materials 256-259: 3043-3048.

http://dx.doi.org/10.4028/www.scientific.net/AMM.256259.3043
Ye, J. 2010. Multicriteria fuzzy decision-making method using entropy weights-based correlation coefficients of interval-valued intuitionistic fuzzy sets, Applied Mathematical Modelling 34(12): 3864-3870. http://dx.doi.org/10.1016/j.apm.2010.03.025

Zavadskas, E. K.; Karablikovas, A.; Malinauskas, P.; Mikšta, P.; Nakas, H.; Sakalauskas, R. 2006. Technology of construction processes. Vilnius: Technika. 547 p. (in Lithuanian).

Zavadskas, E. K.; Turskis, Z.; Antucheviciene, J.; Zakarevicius, A. 2012. Optimization of weighted aggregated sum product assessment, Electronics and Electrical Engineering 122(6): 3-6.

http://dx.doi.org/10.5755/j01.eee.122.6.1810

Titas DE்JUS. Doctor, Associate Professor at the Department of Construction Technology and Management, Vilnius Gediminas Technical University, Lithuania, and expert in occupational safety. Research interests: occupational safety at building sites, the theory of multiple criteria decision-making in practice and improvement of study process.

Jurgita ANTUCHEVIČIENĖ. Doctor, Associate Professor at the Department of Construction Technology and Management, Vilnius Gediminas Technical University, Lithuania. Research interests: sustainable development, construction business management and investment, multiple criteria analysis, decision-making theories and decision support systems. 